\title{
Cooperação internacional em ciência e tecnologia: oportunidades e riscos
}

\author{
International cooperation in science and technology: \\ opportunities and risks
}

DARLY HENRIQUES DA SILVA*

Rev. Bras. Polít. Int. 50 (1): 5-28 [2007]

Introdução

Este trabalho explicita diferenças entre colaboração e cooperação visando entender "as novas formas de trabalho conjunto" observadas desde a década de 80 nos países líderes mundiais em Pesquisa e Desenvolvimento (P\&D) ${ }^{1}$. Pretende chamar a atenção de estudiosos, planejadores e administradores de política de Ciência e Tecnologia (C\&T) no Brasil para a evolução deste tipo de trabalho; a identificação dos parceiros; os motivos que os fazem cooperar, e as condiçóes para o estabelecimento de parcerias. Razões que diferenciam projetos internacionais e parcerias bem sucedidas, de outros que têm seu desenvolvimento comprometido e os objetivos não atingidos. Além disso, a organização em cooperação favorece o setor público quanto à transparência e coordenação, e portanto, é um instrumento de política para evitar anomalias de mercado, como monopólios, que inibem o processo competitivo. Novos tipos de competidores, trabalho conjunto e restruturação industrial, via introdução de novas tecnologias e inovação, inclusive organizacionais com impacto sobre a produtividade, têm acirrado a competição.

A cooperação baseada em $\mathrm{P} \& \mathrm{D}$ enfatizando as alianças estratégicas constitui tema de vários estudos ${ }^{2}$ e seu conceito é crucial para se entender a atividade de

\footnotetext{
* Analista de Ciência e Tecnologia do Conselho Nacional de Desenvolvimento Científico e Tecnológico - CNPQ, Coordenadora Geral de Meteorologia, Climatologia e Hidrologia do Ministério da Ciência e Tecnologia - MCT. É Doutora em Economia pela Universidade de Paris I Sorbonne (França) e possui pós-doutorado em Política de C\&T e Espacial pela Universidade George Washington (darly@mct.gov.br).

1 Ohmae, K. "The Global Logic of Strategic Alliances". Harvard Busisness Review, Mar-Apr. 1989, p. 143-154; Gomes-Casseres, B. The Alliance Revolution: The New Shape of Business Rivalry. Harvard University Press: Cambridge, MA, 1996; Brascomb, M.M.; Keller, J.H. (Eds). Brascomb, L.M; Florida, R. "Challenges to Technology Policy in a Changing World Economy" in Investing in Innovation, MIT Press, 1998.

2 Gibbons, M.et al. The new production of knowledge - The dynamics of science and research in contemporary research. London: Sage Publications, 1994; Etzkowitz, H. et al. "The Future of the University and the University of the Future: Evolution of Ivory Tower to Entrepreneurial Paradigm”. Research Policy, Vol. 29, 2000, p. 313-330; Von Zedtwitz, M; Gassmann, O. "Market Versus Technology Drive in R\&D Internationalization: Four Different Patterns of Managing Research and Development". Research Policy, Vol. 3, 2002, p. 569-588.
} 
$\mathrm{P} \& \mathrm{D}$, por isso, constam do presente texto. Diferente do conceito de alianças em setores estratégicos, alianças ou parcerias estratégicas são novas formas de trabalho conjunto entre parceiros industriais rivais ou não, derivadas dos princípios da globalização. A aliança inaugura uma vantagem competitiva dos parceiros e passa pela inovação, tecnologia e crescimento sustentável. Representa oportunidades, mas, como muitas vezes, a distinção entre o nacional e o internacional é apenas retórica, pode representar riscos para os países em desenvolvimento ${ }^{3}$.

Narula $(2001)^{4}$ discutiu a pertinência de se desenvolver P\&D internamente ou no exterior e, neste último caso, sob que condições. Estudiosos se dedicaram ao exame dos benefícios de consórcios de $\mathrm{P} \& \mathrm{D}$, traduzidos no compartilhamento de custos fixos e na internalização dos aspectos de P\&D entre os participante. Poyago, Beath e Siegel (2002) $)^{5}$ analisaram o crescimento de parcerias universidadeempresa, enquanto Sakakibara $(2003)^{6}$ tratou de inovação e aprendizado relacionados à $\mathrm{P} \& \mathrm{D}$. Wagner $(2002)^{7}$ mostrou como a ciência se imbricou com a política externa em tempos de paz, assunto enfatizado neste trabalho.

\section{Vantagens e desvantagens em cooperar internacionalmente}

Por que cooperar internacionalmente? Porque cooperação é a melhor forma ou apenas o único meio para alcançar objetivos comuns no mundo globalizado. A cooperação internacional abre janelas de oportunidade para os países em desenvolvimento. Mas cooperação requer barganha para se alcançar um acordo, e neste processo, todos os parceiros tentam maximizar seus interesses. Assim, consumar um acordo e sustentá-lo até o final do projeto/programa comum é uma tarefa árdua. ${ }^{8}$ Constituem benefícios da cooperação, o compartilhamento dos custos, o acesso à experiência, tecnologia e instalações. A cooperação serve também como reforço político para o projeto/programa; cria ou estreita boas relações, exerce influência sobre os parceiros e funciona como efeito demonstração de liderança.

Por outro lado, os riscos em cooperar são a perda de liberdade de ação, com a criação de dependências, além do incremento da complexidade gerencial. Riscos políticos se a cooperação falhar; transferência "indesejada” de tecnologia sensível pela comunicação muito pessoal e, ainda, ajuda involuntária em criar ou

3 Kats, J. "Structural reforms and technological behaviour. The sources and nature of technological change in Latin America in the 1990s". Research Policy 30, 2001, p. 1-19.

4 Narula, R. “Choosing Between Internal and Non-internal R\&D Activities: Some Technological and Economic Factors”. Harvard Business Review Technology Analysis \& Strategic Management, Vol. 13, n 3, 2001.

5 Poyago-Theotoky,J.; Beath, J; Siegel, D.S. "Universities and Fundamental Research: Reflexions on the Growth of University - Industry-Partnerships". Oxford Review of Economic Policy, Vol. 18, nº 1, Oxford University Press, 2002, p. 10-21.

6 Sakakibara M. "Knowledge Sharing in Cooperative Research and Development". Managerial and Decision Economics, Vol. 24, 2003, p. 117-132.

7 Wagner, C.S. “The elusive partnership: science and foreign policy”. Science and Public Policy, December 2002, p. 409-415.

8 Logsdon, J.M. Conferência do curso "US Space Policy” realizado pela "Elliot School of International Affairs" da Universidade George Washington, em Washington DC, em 16.10.2003, mimeo, 7 páginas. 
fortalecer futuros competidores ${ }^{9}$. Por isso, os países desenvolvidos reservam uma parte de conhecimento de fronteira e inovação tecnológica ("core technologies") para seu uso exclusivo, a fim de poderem garantir liderança e receber dividendos provenientes de "copyrigths", marcas e patentes, e para tal, empregam todo o aparato legal disponível de proteção à propriedade intelectual e industrial. Tais instrumentos, os países mais desenvolvidos "fazem valer" globalmente, usando os mais diferentes métodos e meios de persuasão, como barreiras não alfandegárias, alfandegárias, comerciais e todo tipo de retaliação, política e econômica ${ }^{10}$. Até nisso, a cooperação é benéfica, pois é capaz de minimizar estes efeitos.

\section{Colaboração e cooperação: modos diferentes de relação internacional}

Colaboração e cooperação têm conceitos diferentes, embora ambas signifiquem "trabalhar em conjunto" e sejam importantes. A colaboração é não eqüitativa e assimétrica, o que implica a existência de um ator principal, responsável pelo projeto/programa e proprietário dos resultados mais interessantes do ponto de vista de aplicação estratégica, industrial e comercial, enquanto os outros membros são apenas coadjuvantes. Em geral, este tipo de trabalho conjunto se limita à assistência técnico-científica, à formação de recursos humanos para a pesquisa, à utilização de equipamentos e laboratórios do membro principal em experimentos conjuntos de interesse maior dos "donos da pesquisa"; à doação de equipamentos usados para países menos desenvolvidos e à instalação temporária e supervisionada em locais privilegiados no território do participante para observação/coleta de dados do membro principal.

Critérios de preferência por parte deste último guiam a colaboração e definem, tanto os participantes, quanto o nível individual de colaboração, o tipo de projeto (piloto ou outro), além do tema do projeto/programa a ser desenvolvido. O controle e a gestão da colaboração ficam por conta do membro principal. Não há confiança mútua. O participante "mais forte", que pode ser individual ou representante de grupos de interesse utiliza os resultados da pesquisa em seu benefício, pois tem um sistema de apropriação e valorização do conhecimento mais ágil e eficiente. Além disso, toma a iniciativa de criar programas intergovernamentais em assunto de interesse geral, como meio ambiente. Muitas das colaborações e projetos em andamento Norte-Sul ${ }^{11}$ na América Latina apresentam este perfil e estas características.

9 Caloghirou, Y; Hondroyannis, G.; Vonortas, N.S. “The Performance of Research Partnerships”. Managerial and Decision Economics, Vol. 24, 2003, p. 85-99.

$10 \mathrm{O}$ acordo nuclear Brasil-Alemanha foi firmado sob enormes pressões norte-americanas. Sobre este assunto vide "A importância da cooperação internacional para o desenvolvimento da ciência brasileira", Krieger, E.M. e Góes Filho, P. de, Parcerias Estratégicas, n 20, Parte 4, junho/2005, Centro de Gestão e Estudos Estratégicos (CGEE)/MCT, p. 1.196-1.198.

11 Aragón, E.L. em "Cooperação Sul-Sul para o Desenvolvimento Científico e Tecnológico da Amazônia", Trabalho apresentado no Seminário Preparatório da $3^{a}$ Conferência Nacional de Ciência, Tecnologia e Inovação, CGEE/MCT, Brasília 15-16.3.2005, mimeo 30 páginas, apresenta definição de cooperação Norte-Sul, Sul-Sul, e Norte-Norte. 
A cooperação surgiu no final da Guerra-Fria com a efetivação dos princípios da détente e da globalização. Houve necessidade de inimigos militares tradicionais, Rússia e Estados Unidos (EUA) trabalharem juntos, tanto para evitar a transferência de tecnologia sensível (nuclear e espacial) dos russos para países "indesejados" pelos americanos, como o Iran, por exemplo, quanto para contribuir para o aumento da competência dos aliados militares dos EUA, que são simultaneamente seus competidores comerciais, em especial, a Europa Ocidental e o Japão.

Monitorar estas atividades mundialmente, bem como manter sigilo industrial e estratégico intramuros ficou muito difícil para os EUA, graças à difusão da informação e comunicação de alta tecnologia em escala global. A mudança foi também influenciada pela chegada em cena de novos atores, países não-alinhados, com intenção de desenvolver atividades nucleares, além do crescimento exponencial de não-estados. Ademais, organizações do terceiro setor em geral passaram a ter um papel ativo em C\&T.

Como resultado, a colaboração teve que evoluir para parceria mais eqüitativa, privilegiando o diálogo, a negociação, a decisão conjunta, a definição de projetos em comum acordo e o compartilhando dos custos, sobretudo os de P\&D.

O grande diferencial entre as duas formas de "trabalhar junto" coloca à disposição da cooperação, o que cada parceiro tem de melhor, e de maneira complementar, mas sempre garantindo a independência de cada membro. Coordenação substituiu controle, e o exercício da confiança passou a ser o princípio básico em prol da parceria. Os resultados da cooperação pertencem aos parceiros, segundo definição previamente acordada, proporcional ao esforço de cada um, pois há confiança entre eles.

Os arranjos legais tornaram-se gradativamente menos formais, e com isso, permitem maior flexibilização das organizações envolvidas. Cada parceiro traz para a cooperação o que sabe fazer de melhor. Por este motivo, entram em cooperação. O processo cooperativo põe em evidência a ausência direta de disputa em termos de apropriação do conhecimento e de tecnologias entre os parceiros. Para isso, os acordos e convênios trazem cláusulas de propriedade intelectual e industrial e todos respeitam porque confiam uns nos outros. Este é o principal motivo para se entrar em parceria: todos ganham. Cooperar para competir com outros fora da parceria é a meta.

A colaboração bem sucedida pode evoluir para cooperação. Um ponto essencial na cooperação é que ela agrega funçōes e age transversalmente, assim, não se limita à segmentação setorial. Reúne conhecimento tácito ${ }^{12}$, "kowhow" e financiamento próprio. Cada parceiro é co-responsável pelo sucesso do

12 Conhecimento não-codificado ou escrito, pessoal ou institucional, segundo, dentre outros, Brooks, H. "The relationship between science and technology", Research Policy, 23 September 1994, p. 485; Bell, M e Pavitt, K. em "Technological accumulation and industrial growth: contrasts between developed and developing countries", in Technology, Globalisation and Economic Performance, Archibugi, D. e Michie. J (Eds), Cambridge University Press, 1997, p. 92. 
empreendimento. Este procedimento facilita o aprendizado organizacional. A parceria é uma sociedade em que as regras são conhecidas, aceitas e respeitadas pelos seus membros. Os conhecimentos multidisciplinar e multisetorial enriquecem as alianças, tornando-as atraentes em termos de competitividade.

Vários anos de aprendizagem em trabalhar conjuntamente sob estas novas bases foram necessários, sobretudo nas parcerias de gerência/gestão compartilhada de programas e projeto $^{13}$. Cooperação significa decisão conjunta, desde o planejamento até a execução e avaliação final, bem como correção de rota para projetos de médio e longo prazos.

As chances de sucesso da parceria aumentam com os esforços em absorver conhecimentos anteriores de cada parceiro e os adquiridos na parceria. Parcerias bem sucedidas motivam a realização de outras, mais audaciosas, exigindo mais conhecimento, confecção de trabalhos mais elaborados; compartilhamento mais eqüitativo em termos de financiamento de cada um, e às vezes, conquista de fatias de mercado que as parcerias internacionais promovem e facilitam.

\section{Origens e características das alianças estratégicas}

Desde quando as parcerias começaram a se desenvolver, passaram por várias fases. Isto permitiu adaptações dos países que perceberam, de início, as mudanças provocadas internamente, que ocorreram como resposta ao contexto externo, cujas mutaçóes, eles próprios produziram. Como conseqüência maior destas transformações, as firmas destes países não mais se apóiam na sua P\&D para se manterem tecnologicamente competitivas. Este aspecto diferenciou o modo de agir das empresas multinacionais que, anteriormente, retinham os seus laboratórios de $\mathrm{P} \& \mathrm{D}$ na sede, e, conservavam os rivais à distância.

A partir de meados dos anos 80, o desenvolvimento tecnológico e econômico mundial foi guiado pela globalização e seus corolários, a détente (aspecto político) e a desnacionalização e internalização (componentes econômicos) que se somaram para influenciar o modo de produzir e de comercializar em escala planetária.

Em resposta a tais mudanças e com o acirramento da competição, essas firmas passaram a se agrupar em alianças estratégicas, associando-se, não raro, com concorrentes, nacionais e internacionais, para sobreviverem no mercado globalizado. Foi um período marcante de fusões e aquisições de firmas, bem como da reestruturação de setores industriais tradicionais, através de rearranjos organizacionais.

O termo aliança ou parceria estratégica foi introduzido nesta ocasião. De um modo geral, aliança ou parceria estratégica se refere a acordos em que dois ou

13 Vonortas, N. S. Cooperation in Research and Development. Kluwer Academic Publishers, 1997; Georghiou, L. "Global Cooperation in Research", Research Policy, Vol. 27, 1998, p. 611-626.; Link, N.A; Paton, D; Siegel, D.S. "An analysis of policy initiatives to promote strategic research partnerships". Research Policy, Vol. 3, 2002, p. 1.459-1.466; Caloghirou, Y; Hondroyaiannis, G.; Vonortas, N.S. op. cit., Ref. 9. 
mais parceiros compartilham o compromisso de alcançar um objetivo comum, reunindo seus recursos e coordenando suas atividades. Alianças denotam um certo grau de estratégia e de coordenação operacional e devem envolver investimentos de cada uma das partes. Não há repasse de recursos financeiros entre os parceiros.

Nem todas as parcerias são alianças estratégicas na concepção de Yoshino $^{14}$, adotada pelas Nações Unidas e neste trabalho. As excluídas, como fusões e aquisições, contratos de subsidiárias externas de firmas multinacionais e acordos de "franchising" não são alianças estratégicas porque não envolvem firmas independentes, com objetivos separados, ou que apelem para contribuição continuada de firmas participantes quanto à transferência de tecnologia ou a habilidades dos parceiros.

No esforço de explicar as mutaçóes então observadas, conceitos novos e correlatos passaram a compor a literatura sobre as "novas formas de trabalho conjunto" das firmas.

Redes são as organizações cooperativas interligadas que criam, adquirem e integram os diversos conhecimentos e capacidades necessárias para inovar tecnologias complexas. Exemplos destas ligações organizacionais em redes são as alianças estratégicas. Consórcios, utilizando alianças estratégicas, apresentam também esta estrutura e são largamente empregados em cooperação internacional com vários membros. As alianças estratégicas provêem as unidades onde elas são empregadas com flexibilidade, deixando-as aptas a responderem às mudanças que ocorrem no mercado, e a reagirem ao aparecimento de novos competidores.

A tecnologia é a engrenagem das economias poderosas das sociedades pós-industriais. As inovações tecnológicas caracterizam-se por processos autoorganizáveis nas firmas e nos atores. Não há um controle central para arranjar as capacidades tecnológicas e recombinar as antigas. As redes de inovação são auto-organizáveis e estão vinculadas ao processo de globalização, na medida em que as mudanças organizacionais e tecnológicas ajudam a criar os mercados e a viabilizar a participação de outras instituições. Tais redes são capazes de aprender por interação. Para isso, desenvolvem relaçôes de confiança entre as partes.

Correspondentemente, as instituições políticas e econômicas modificam as novas organizaçōes e, também, as inovaçōes tecnológicas. A organização/ administração das instituições é tão importante quanto as atividades de $\mathrm{P} \& \mathrm{D}$, pois delas depende a efetividade da inovação, até a sua chegada ao mercado. A flexibilidade das redes e sua renovação são essenciais para as mudanças nas demandas do mercado. Tais redes precisam responder de maneira competitiva, mas devem ser capazes de se adaptar de forma a influenciar o meio a que têm acesso. Há uma auto-organização quando firmas tentam diversificar sua capacidade e aumentar seus recursos, e para isto, buscam parceria.

14 Citado por Kang, N-H.; Sakai, K, p. 7, International Strategic Alliances: Their Role in Industrial Globalisation, Organization for Economic Co-operation and Development (OCDE) (2000)5. 
As alianças estratégias são orientadas pelas demandas do mercado globalizado, custos da sua rápida inovação e pelas oportunidades que se abrem pela regulamentação e as iniciativas de liberalização. Seguindo este padrão, mais de 10.000 alianças estratégicas internacionais em tecnologia foram formadas nos anos 90. Os EUA contribuíram com $80 \%$ das alianças estratégicas, nacionais (maioria) e internacionais. Projetos cooperativos foram intensamente usados pelo Japão e o governo coreano lançou uma série de programas cooperativos de $\mathrm{P} \& \mathrm{D}$ desde $1982 . .^{15}$

Uma reação a tal movimento ocorreu na Europa Ocidental associada à questão do emprego. As barreiras para mudar foram muitas, pois exigiam alto investimento ${ }^{16}$. Foi um período de transformações organizacionais profundas no setor industrial de vários países que se prepararam para uma nova etapa, com a intervenção decisiva dos respectivos poderes públicos, mesmo por parte dos adeptos do livre-comércio. O que estava em jogo, na ocasião, era a competitividade das indústrias e a sua sobrevivência, inclusive as americanas que apontavam deficiências em relação à japonesa que introduzira inovação organizacional no seu setor produtivo anos antes.

Conselheiros em política de C\&T dos EUA alertaram o governo sobre a necessidade de as políticas tecnológica e industrial serem renovadas para tratarem com as complexidades tecnológica e organizacional para manter a liderança do seu país ${ }^{17}$. Estudos acadêmicos e, também, de organismos internacionais, visando a criação de políticas públicas se dedicaram, a partir de então, a orientar os governos para tirarem o máximo proveito da "nova ordem econômica" que se formava. O objetivo para os países da Organização para a Cooperação e Desenvolvimento Econômico e para as naçóes em desenvolvimento, era no sentido de os governos incentivarem a indústria nacional a se engajarem em processos inovativos, utilizando a nova maneira de organização. Dunning $(1998)^{18}$, por exemplo, se dedicou ao exame do efeito que alianças estratégicas tiveram sobre o desempenho industrial.

O Brasil se engajou neste movimento para responder a demandas tecnológicas, mas sem se dar conta do processo global de difusão em curso e do impacto que teriam nos anos seguintes. A crise econômica que se abateu sobre o Brasil, aliada à necessária democratização naquele momento (anos 80$)$, desviaram a atenção e o esforço nacionais sobre as questōes tecnológicas e as implicações que as parcerias vinham provocando mundialmente.

15 Narula, R.; Hagedoorn, J. "Innovating through strategic alliances: moving towards international partnerships and contractual agrrements", Technovation 19, may 1999, p. 283-294.

16 Sachwald, F. "Cooperative Arguments and the Theory of the Firm. Focusing on the barriers to change". Journal of Economic Behavior \& Organization, Vol. 35, 1998, p. 203-225.

17 Rycroft,R.W.; Kash, D.E. "Innovation Policy for Complex Technologies". Issues in Science and Technology, Fall 1999, p. 7379 .

18 Dunning, J.H. "Location and the Multinational Enterprise: a Neglected Factor". Journal of International Business Studies, Vol. 29, n 1, 1998. 
Ora, os países que geram inovação são os que produzem e detém tecnologia. São também os que mais rapidamente criam ou adaptam suas estruturas industriais e organizacionais para facilitar a adoção e difusão de novas formas de produzir. Eles são os maiores usuários das parcerias formais, das quais uma faixa estreita contempla inovação, pois o mapa da inovação é muito restrito a alguns países desenvolvidos. Os países em desenvolvimento utilizam parcerias estratégicas, mas representam menos de $5 \%$ do total mundial. ${ }^{19}$ Este percentual indicou para vários estudiosos que os países em desenvolvimento estavam ficando para trás nos setores emergentes. Parcerias baseadas em P\&D são importantes pois impactam sobre a capacidade industrial dos participantes. Um grande número de parcerias se destina a atividades como marketing ou somente P\&D, refletindo o papel crescente de firmas de serviço em parcerias internacionais.

\section{Mudanças conceituais envolvendo inovação e reforçando o papel de parcerias}

O que mais distingue o período contemporâneo dos anteriores é que inovações a custos competitivos resultam da organização de pessoas comuns, com treinamento avançado em trabalho em grupo, e que consideram a inovação como propósito coletivo. Parcerias podem ocorrer verticalmente através das cadeias de valor, desde os fornecedores de matérias-primas, passando pela pesquisa, design, produção e montagem de partes, até a distribuição de produtos e serviços. Parcerias horizontais envolvem competidores no mesmo nível da cadeia de valor $^{20}$. Parceiros podem ter suas bases em um ou mais países, no último caso, criando cooperação internacional. Enfim, estudos foram dedicados a classificar os vários tipos de parceria como o de Hagedoorn $(2002)^{21}$ usando diferentes níveis de interdependência organizacional entre os parceiros desde 1960.

Há alguns anos, os sistemas nacionais de inovação se organizam para favorecer o aparecimento e facilitar a utilização e difusão de inovação. Embora sistemas nacionais de inovação existam em vários países há anos ${ }^{22}$, no Brasil, ele não foi implantado, e isto, por vários motivos discutidos, com detalhe por Meyer-Stamer $(1995)^{23}$ e cujos argumentos continuam válidos. Nos EUA, no âmbito do sistema de inovação, as mudanças políticas incluíram a expansão de programas para apoiar parcerias tecnológicas público-privadas, a relaxação da lei "antitruste" para

19 Kang, N-H; Sakai K. International Strategic Alliances: Their Role in Industrial Globalisation, OCDE, (2000)5, p. 13

20 United Nations. Partnership and Networking in Science and Technology for Development, Technology Series - United Conference on Trade and Development, New York and Geneva, 2002, p. 31.

21 Hagedoorn, J. "Inter-Firm R\&D Partnership - An Overview of Major Trends and Patterns since 1960". Research Policy, Vol. 31, 2002, p. 477-492.

22 Nelson, R.R. National Innovation Systems. A Comparative Analysis. New York-Oxford, Oxford University Press, 1993.

23 Meyer-Stamer, J. "New Departures for Technology Policy in Brazil". Science and Public Policy, Vol. 22, No 5, 1995, p. 295-304. 
promover a pesquisa cooperativa, e a adoção de várias iniciativas para proporcionar uma difusão mais rápida de tecnologias das universidades e laboratórios federais para as firmas. O mecanismo usado foi o de parcerias estratégicas de pesquisa ${ }^{24}$.

Muitas vezes, entidades públicas e privadas que realizam P\&D necessitam apenas do nome de instituições para legitimarem sua ação. É a marca de produtos/ projetos de pesquisa, ou de instituições que lhes conferem status e legitimam suas ações conferindo-lhes aval. $\mathrm{O}$ processo de desnacionalização promoveu esta atividade em nível industrial. Como a obtenção de uma marca é dispendiosa, um parceiro pode usar a marca de outro legitimado no mercado, para fabricar produtos fora do país de origem da marca. Isso é fruto de colaboração entre os diversos atores do Sistema Nacional de C\&T, os sistemas político, econômico, e quando existente, com o de inovação.

\section{Dificuldades de adaptação abaixo do Equador}

Tirar o máximo proveito de parcerias foi o objetivo de vários países. Para isto, tiveram que se preparar e, consequentemente, investir nas suas estruturas industriais, de C\&T e em novos conhecimentos, o que provocou o avanço da fronteira da ciência, propiciou a criação de novos produtos e promoveu a inovação tecnológica. Ora, os anos 80 e 90 foram marcados por crises financeiras e econômicas em nível mundial e que demonstraram o nível de globalização das naçôes, com impacto extremamente negativo sobre as economias da América Latina. Porém, sabe-se que é em épocas de crise que as oportunidades aparecem, e assim, alguns países em desenvolvimento conseguiram resolver seus problemas internos, pois gozavam de alguns escudos de proteção contra a especulação financeira, e lograram prosperar moderadamente ${ }^{25}$. Isto pode ser observado nas estatísticas deste período.

As Naçōes Unidas ${ }^{26}$, usando a base de dados Merit-Cati, listou as 25 firmas mais ativas em parcerias tecnológicas nos países em desenvolvimento no período 1980-1994, nos setores eletro-eletrônico, automobilístico, aviação, químico, aeroespacial, telecomunicações e petroquímico. De um total de 217 projetos de parceria, o Brasil está representado apenas pela Embraer e com 3 parcerias, enquanto que a Coréia do Sul, liderando o grupo, comparece com 10 empresas e 100 parcerias, e a Arábia Saudita com 16 parcerias e uma única empresa, sendo que este país investe pesadamente nos EUA.

Estes dados sugerem que, ao invés de os analistas brasileiros de C\&T compararem somente o número de patentes de países, como o fazem sistematicamente com o Brasil e a Coréia, um outro indicador interessante de desempenho tecnológico e

24 Vonortas, N.S.1997, op. cit. Ref. 13.

Link, N.A., Paton, D. and Siegel, op. cit. Ref. 13.; Audretsch, D.B. "Strategic Research Linkages and Small Firms”. Strategic Research Partnerships, Porceedings National Science Foundation Workshop, July 2001.

25 Vonortas, N.S. Building competitive firms: technology policy initiatives in Latin America, Technology in Society, Vol. 24, 2002, p. 433-459.

26 United Nations, 2002, op. cit. Ref. 20. 
industrial é o do número de empresas e de suas parcerias estratégicas, nacionais e internacionais. Nem sempre empresas patenteiam seus resultados, por segurança e/ ou segredo industrial. Pouco ou nada, porém, tem sido feito para incluir nos estudos desses analistas, parcerias estratégicas ou outras formas cooperativas que traduzem as atividades de P\&D nas empresas. Enquanto patente é indicador de "output" de uma parte da atividade de $\mathrm{P} \& \mathrm{D}$, o número de parcerias estratégicas por empresa é indicador de "input" da mesma atividade, guardando relação de dependência com o desempenho final. A propósito, a Embraer e a Petrobrás dispõem de poucas patentes se comparadas com empresas de outros países, mas têm alianças estratégicas, e são empresas líderes no Brasil com mercado internacional para seus produtos.

Uma explicação possível para este comportamento e a metodologia usada nos estudos mencionados é que a análise da política tecnológica no Brasil tem um viés conceitual. Trata-se da sua ligação com o debate da política industrial, realizada por especialistas em política científica. O motivo é que o Brasil ficou os últimos 25 anos sem uma política industrial, recriada em 2004. Neste período, entretanto, se organizou uma comunidade em política de $C \& T$ no País, que usou intensivamente o modelo linear de mudança técnica. Neste modelo, o desenvolvimento da tecnologia é "input" necessário para a indústria, cujo desempenho é medido pelo número de patentes. Os setores de aviação e aeroespacial são os maiores contra-exemplos desta "lógica". A propósito, redes de cooperação só começaram a ser estudadas no Brasil bem mais recentemente, e, não necessariamente, com o mesmo enfoque e os mesmos conceitos internacionais, uma vez que no exterior, elas se desenvolveram como teorias da firma, e no Brasil, como atividades de C\&T em geral, com ênfase na pesquisa ou ligadas à análise de blocos regionais, como por exemplo, em Velho $(2001)^{27}$.

Os novos países industrializados contam, entretanto, com um diferencial nas suas políticas tecnológicas e industriais representados pelas alianças ou parcerias estratégicas por setor industrial, pelo menos desde a década de 80 (Tabela 1).

Tabela 1

Distribuição das parcerias estratégicas em tecnologia nos países em desenvolvimento no período 1980-1994.

\begin{tabular}{l|c|c|c|c}
\hline \multicolumn{1}{c|}{ Setor industrial } & $\begin{array}{c}\text { Novos países } \\
\text { industrializados }\end{array}$ & $\begin{array}{c}\text { Leste } \\
\text { Europeu }\end{array}$ & $\begin{array}{c}\text { América } \\
\text { Latina }\end{array}$ & $\begin{array}{c}\text { Outros países em } \\
\text { desenvolvimento }\end{array}$ \\
\hline Biotecnologia & 40.74 & 18.52 & 14.81 & 25.93 \\
\hline Tecnologia da informação & 65.22 & 7.83 & 3.48 & 23.48 \\
\hline Novos materiais & 52.17 & 13.04 & 8.70 & 26.09 \\
\hline Setores de alta tecnologia & 37.50 & 25.00 & 6.25 & 31.25 \\
\hline Setores de média tecnologia & 35.15 & 6.06 & 5.45 & 53.33 \\
\hline Setores de baixa tecnologia & 6.25 & 6.25 & 6.25 & 81.25 \\
\hline
\end{tabular}

Fonte: Adaptado de Merit-Cati Database (Narula \& Sadowski, 2002, p. $613^{28}$ ).

27 Velho, L.S. "Redes Regionais de cooperação em C\&T e o Mercosul”. Parcerias Estratégicas, CGEE/MCT, no 10 , Março 2001, p. 58-74.

28 Narula, R; Sadowski, B.M. "Technological catch-up and strategic technology partnership in developing countries". International Journal of Management, Vol. 23, 2002, p. 599-617. 
Um outro indicador para medir essas atividades diz respeito às remessas brasileiras ao exterior de contratos de transferência de tecnologia. Conforme a Tabela 2, há uma tendência de diminuição destas remessas a partir de 1999, em relação a marcas e patentes licenciadas no exterior.

Tabela 2

Remessas ao exterior por contratos de transferência de tecnologia e correlatos, 1992-2002 (em mil US\$ correntes)

\begin{tabular}{c|c|r|r|r|r|c}
\hline \multirow{2}{*}{ Ano } & \multirow{2}{*}{ Total } & $\begin{array}{c}\text { Fornecimento } \\
\text { de serviço de } \\
\text { assistência } \\
\text { técnica (1) }\end{array}$ & $\begin{array}{l}\text { Fornecimento } \\
\text { de tecnologia }\end{array}$ & $\begin{array}{c}\text { Marcas: } \\
\text { licença de } \\
\text { uso/cessão }\end{array}$ & $\begin{array}{c}\text { Patentes: } \\
\text { licença de } \\
\text { exploração/ } \\
\text { cessão }\end{array}$ & Franquias \\
\hline 1992 & 160.484 & 126.352 & 31.250 & 2 & 2.880 & $\ldots$ \\
\hline 1993 & 227.419 & 146.018 & 41.660 & 44 & 39.697 & $\ldots$ \\
\hline 1994 & 373.222 & 244.096 & 48.266 & 1.756 & 79.104 & $\ldots$ \\
\hline 1995 & 652.014 & 286.217 & 222.164 & 5.013 & 138.620 & $\ldots$ \\
\hline 1996 & 960.564 & 368.749 & 378.154 & 13.237 & 200.424 & $\ldots$ \\
\hline 1997 & 1.454 .260 & 760.971 & 512.545 & 14.060 & 166.684 & $\ldots$ \\
\hline 1998 & 1.756 .327 & 1.017 .959 & 540.113 & 12.529 & 182.747 & 2.979 \\
\hline 1999 & 1.553 .354 & 931.790 & 482.266 & 37.939 & 97.083 & 4.276 \\
\hline 2000 & 1.802 .231 & 1.045 .747 & 619.476 & 31.160 & 94.436 & 11.412 \\
\hline 2001 & 1.704 .521 & 1.085 .642 & 505.126 & 28.134 & 75.069 & 10.550 \\
\hline 2002 & 1.581 .915 & 1.005 .203 & 485.439 & 22.163 & 59.102 & 10.008 \\
\hline
\end{tabular}

Fonte: Banco Central do Brasil/Departamento Econômico (DEPEC)/Divisão de Balanço de Pagamentos (DIBAP). Elaboração: Coordenação Geral de Indicadores - Ministério da Ciência e Tecnologia, 2004

Nota: inclui serviços técnicos especializados em implantação e instalação de projetos. Nem todos os contratos contabilizados sob essa rubrica são averbados pelo Instituto Nacional de Propriedade Industrial por não serem considerados como transferência de tecnologia.

Isto sugere que o Brasil pode estar substituindo ou modificando o perfil dos bens e serviços que produzia sob licença internacional, graças ao incremento de $\mathrm{P} \& \mathrm{D}$ desenvolvido internamente, talvez por meio de parcerias estratégicas. Isto pode, consequentemente, ser resultado de políticas públicas setoriais aplicadas à indústria, apesar da ausência de política industrial explícita no período. Em se comprovando esta hipótese, com a tendência se confirmando no longo prazo, este comportamento é muito positivo para a política industrial brasileira. Franquia e assistência técnica que apontam crescimento mais recentemente não são parcerias estratégicas mas sim as marcas e patentes, que diminuíram a partir de 1999.

\section{Cooperação internacional e seus pré-requisitos}

Por que algumas parcerias internacionais dão certo e outras não? Estudos sobre o assunto apontam para a existência de pré-requisitos para que parcerias 
sejam bem sucedidas. As principais são: a escolha dos parceiros, a definição conjunta do tema da pesquisa ou do projeto; a divisão de trabalho; os objetivos a serem alcançados; as condições materiais e intangíveis de cada membro. Isto define o grau e a natureza do trabalho conjunto, que pode ser, desde uma assistência técnica à uma genuína cooperação, passando pela colaboração. Manter a cooperação internacional exige condições como comprometimento, algumas de Chefes de Estado, confiança e respeito dos parceiros, cumprimento dos objetivos comuns e de tudo que foi acordado entre eles.

O Brasil integra com mais 15 países, o programa da Estação Espacial Internacional (ISS). Para implementá-lo, a agência espacial americana (NASA) firmou acordos bilaterais com as suas congêneres na Europa, Japão, Canadá e Brasil e o presidente americano assinou um Acordo Intergovernamental com os chefes de Estado de cada país-membro. Isto só foi possível para o Brasil após a inclusão de um adendo sobre a participação brasileira na ISS no Acordo-Quadro sobre o Uso Pacífico do Espaço Exterior assinado entre o Brasil e os EUA em 1996. A contribuição do Brasil se deu a convite do presidente americano para a realização de uma parcela da tarefa da NASA que detém cerca de $50 \%$ do consórcio, com barganha comandando a negociação que viabilizou a participação do Brasil como colaboração (participante), enquanto a participação dos outros 15 membros (parceiros) configura cooperação horizontal Norte-Norte ${ }^{29}$.

Mesmo quando se trata de parceiros de C\&T dentro de um bloco comercial, é necessário distinguí-los. Argentina, Paraguai e Uruguai não têm a mesma história de cooperação com o Brasil.

Grandes temas com forte apelo político, como espaço, nuclear, e energia, mudanças globais exigem uma intervenção diferente dos temas menos "sensíveis". Entretanto, historicamente, têm servido de carro-chefe para alavancar outros setores de interesse para a sociedade, utilizando cooperação internacional.

$\mathrm{O}$ tratamento e a prática da cooperação internacional demandam um conhecimento prévio dos elementos que lhe são intrínsecos. Identificar o interlocutor/parceiro é uma tarefa fundamental para as etapas seguintes. Assim, se o projeto/programa diz respeito à parceria formal, entre Estados, a metodologia aplicável é analisar os interesses mútuos e áreas nas quais a colaboração ou cooperação é desejável. Esta metodologia se justifica, pois, geralmente, parceria deste tipo começa com a definição de áreas de interesse mútuo, seguida de missões exploratórias cujas recomendaçôes subsidiam acordos bilaterais posteriormente.

Para isto, há procedimentos padrão e arranjos legais específicos, como memorandos de entendimento, visitas técnicas e científicas, seguidas de "workshops" fundamentais para a definição dos termos de referência que comporão os documentos básicos de formalização da cooperação. Neles ficarão explicitados os papéis de

29 Silva, D.H. da. "Brazilian Participation in the International Space Station (ISS): commitment or bargain struck?” Space Policy, Vol. 2, 2005, p. 55-63. 
cada parceiro, os objetivos; recursos empregados, fonte de investimento, formas de avaliação, enfim, tudo que for necessário ser acordado na aliança, sendo que a atualização periódica dos acordos é fundamental.

Acordo-quadro e convenção-quadro de cooperação em C\&T entre nações assinados pelos seus mandatários dão respaldo legal e político às parcerias. Estabelecem os princípios e regras gerais, mas não estipulam prazos nem obrigaçôes específicas. Têm força de lei nos países que os ratificam, porém não garantem o cumprimento das suas determinações. Alguns setores, envolvendo questôes estratégicas e complexas como espaço e nuclear (não existe acordo de transferência de tecnologia de bens sensíveis) necessitam de tratados ratificados pelo Congresso Nacional, conforme rege a Constituição Federal.

Existe uma hierarquia entre esses acordos dependendo da sua natureza, do grau de avanço das negociações e do número de nações signatárias. Por exemplo, Protocolos podem avançar para Tratados, como o de Kyoto, em vigor, após a ratificação pela Rússia, embora os EUA não tenham aderido e dificilmente o farão pois utilizam como fonte de energia, preponderantemente, o carvão mineral $(-80 \%)$.

Outro exemplo de funcionamento de negociação internacional complexa é o acordo de salvaguardas para o uso da base de lançamentos de Alcântara por satélites comerciais (80\% americanos) assinado entre o Brasil e os EUA em 2000 e que necessita ser ratificado pelo Congresso Nacional, com pendência até hoje. Casos especiais são autorizados pela Advocacia Geral da União, como o estabelecimento recente da empresa binacional Brasil-Ucrânia na área espacial.

A reboque do compromisso político vem o comprometimento financeiro para que acordos ou convênios não passem de meros exercícios coletivos sem possibilidade de realização e de alcance dos objetivos propostos. Acordos internacionais com o Brasil precisam de "aval" político, pois a credibilidade nacional ainda está sendo testada por parceiros externos em projetos de longo prazo e garantia de fluxo de caixa. Parcerias internacionais com o Brasil bem sucedidas tiveram o apoio mencionado, como a do programa CBERS (China Brazil Earth Resources Satellites).

\section{Por que C\&T está na agenda de política externa?}

C\&T é uma componente transversal de várias atividades econômicas e sociais. Assim existe uma tendência de os parceiros de P\&D se congregarem em torno de idéias e de projetos comuns tendo como objetivo final essas e outras atividades. A finalidade é minimizar gastos em infra-estrutura e valorizar a fertilização cruzada de conhecimentos, ou seja, com retroalimentação, e não de maneira linear. Este é um ponto comum à cooperação, que tem a mesma característica: é também transversal e rompe com os setores, agregando funções. Não é sem motivos que redes e "clusters", alimentados por alianças estratégicas 
e outras formas de arranjos cooperativos, apresentaram crescimento explosivo nos últimos anos, e se tornaram instrumentos poderosos na estratégia de firmas, governos e comunidades científico-tecnológicas dos países avançados, rompendo e ultrapassando barreiras geográficas.

Uma pequena parcela das atividades de P\&D fica protegida dentro dos países desenvolvidos, por motivos de segurança nacional ou proteção à propriedade intelectual e industrial. Outras atividades, mesmo as que geram inovação, porém de itens que demandam menos recursos financeiros, tempo de pesquisa e maturação tecnológica são entregues à parceria internacional sob várias formas, como alianças estratégicas e terceirização (outsourcing que tem a Índia como recordista em Tecnologia da Informação). Estas são maneiras de cooperar menos formais, mais ágeis, sem necessidade de os parceiros criarem uma empresa nova como nas joint-ventures. Como o marco legal é flexível, o compromisso maior volta-se para criar, promover e conservar laços de confiança entre os parceiros.

Além disso, a transversalidade da C\&T facilita o diálogo entre os atores políticos e a retomada de negociações entre nações. Consequentemente, é útil para compor agenda de política externa. A propósito: "A viagem a Washington se insere, assim, na estratégia de construção de uma agenda positiva entre Brasil e Estados Unidos, pela via científico-tecnológica.", afirmou o ex-Ministro da C\&T em $2002^{30}$.

As comunidades científicas têm experiência em trabalho conjunto sob várias formas, e por isso, têm servido de facilitadores para abrir canais de diálogo com outros atores, sobretudo os governamentais e industriais, mesmo em setores protegidos. Enquanto representantes suprapartidárias, a Academia Brasileira de Ciências e a Sociedade Brasileira para o Progresso da Ciência atuam como interlocutores com instâncias políticas. Peças-chave dentro de embaixadas, adidos científicos desempenham papel primordial em criar oportunidades de parceria com instituições de C\&T nos países onde estão credenciados. Ciência, tecnologia e política externa se somam, mais do que nunca, mas de forma diferente da que fizeram durante e logo após a Segunda Guerra Mundial ${ }^{31}$.

\section{Cooperação Internacional: instrumento de economia e geopolítica}

Dada a importância da cooperação internacional para a aproximação entre os povos, mas regida por interesses políticos e econômicos, o papel principal desta atividade tem sido conduzido pelos próprios chefes de Estado e suas altas administrações. Governos utilizam-se de colaboração internacional por vários motivos, que desde o final da Guerra-Fria, combinam C\&T com geopolítica e economia. As visitas de governantes a países com os quais mantém relações de

30 Relatório da Missão aos EUA do Ministro de Estado da Ciência e Tecnologia de 17 a 24 de abril de 2002, mimeo, $17 \mathrm{p}$.

31 Wagner, C.S.2002, op. cit. Ref. 7. 
amizade são sempre uma ocasião propícia para incluírem na pauta de negociação, itens relacionados à C\&T, como meio de reforçar suas economias e posições comerciais e geopolíticas ao redor do mundo. Em geral, tais itens compõem a agenda maior de política externa de cada país. A propósito, não há dúvidas quanto à importância da visita do presidente Nixon à China em 1972, inaugurando uma nova era no relacionamento internacional em escala planetária, enquanto que apenas um século antes, a frota americana sob comando do Comodoro Perry havia obrigado o Japão a se abrir para o comércio ocidental e a assinar tratados à força. A aproximação com a China resultou em intensa parceria através de alianças estratégicas utilizando, desde então, conhecimento científico e tecnológico entre os dois países. ${ }^{32}$ No início, os EUA prestaram assistência técnico-científica devido ao estado de deficiência em que se encontrava a C\&T resultante de anos de isolamento, principalmente em termos institucionais. Na mesma linha, a visita do Presidente Sarney à China em 1988 e a negociação de um projeto conjunto de satélites de sensoriamento remoto CBERS rendeu seus frutos. ${ }^{33}$ Em 1985, compartilhando projetos comuns, os Presidentes Raul Alfonsin e José Sarney assinaram a Ata de Iguaçu, dando início à histórica aproximação Brasil-Argentina que resultou na criação do Mercosul em 1991. Com os países do Mercosul, a cooperação representa a sobrevivência deste mercado regional. ${ }^{34}$

Dadas as condições econômico-financeiras da maioria dos países da América do Sul, tem cabido ao Brasil a maior parte do financiamento das atividades de C\&T do bloco, como o Programa Sul Americano de Apoio às Atividades de Cooperação em Ciência e Tecnologia do Brasil com os Países da América do Sul (Prosul) ${ }^{35}$. A cooperação Sul-Sul tem sido muito fraca, desconsiderando-se as instituições científicas em países em desenvolvimento, capazes de transferir conhecimentos, que atuando de maneira coordenada e cooperativa, poderiam reforçar sua capacidade científica e de negociação ${ }^{36}$.

A política externa adotada pelo atual governo brasileiro é a de procurar parceiros fora do eixo tradicional, ou seja, da tríade EUA-Europa Ocidental e Japão, expandindo a sua atuação internacional e abrindo novos mercados para a sua economia, embora a diferença em relação ao governo anterior seja mais de estilo do que na substância, de acordo com Almeida ${ }^{37}$. Entretanto, parcerias

32 Kang, N-H, Sakai, K. OCDE, (2000)5, p. 13. op. cit. Ref. 19.

33 Costa Filho, E. J. A Dinâmica da Cooperação Espacial Sul-Sul: O Caso do Programa CBERS (China-Brazil Earth Resources Satelitte), tese apresentada ao Instituto de Geociências da Universidade de Campinas para obtenção do título de Doutor em Política de Ciência e Tecnologia, 2006.

34 Velho, L. Redes Regionais de Cooperação em C\& T, março 2001, op. cit. Ref. 27 e Redes Regionais de Cooperação em C\&T e o Mercosul, Síntese Final, MCT, 1997, mimeo, 60 páginas.

35 Dias, L.C. "Programa Sul-Americano de Apoio às Atividades de Cooperação em Ciência e Tecnologia do Brasil com Países da América do Sul (Prosul)", Parcerias Estratégicas, no 20, Parte 4, junho de 2005, CGEE/MCT, p. 1.247-1.268.

36 Aragón, L. E., 2005, op.cit. Ref. 11.

37 Almeida, P.R. de. "Uma Política Externa Engajada: A Diplomacia do Governo Lula", Revista Brasileira de Politica Internacional, vol. 47, no 1, 2004, p. 162-184. 
com a tríade, significam para o Brasil, a constante e necessária renovação de conhecimentos fundamentais para manter-se atualizado e participante em projetos conjuntos com os produtores de conhecimento de ponta, de tecnologia e de inovação tecnológica ${ }^{38}$.

Com países de economia em transição e novos parceiros, o relacionamento é interessante e estratégico para o Brasil, como o BRIC (Brasil, Rússia, Índia e China) ${ }^{39}$, grupo estimado em ter uma posição de liderança mundial por volta de 2025, segundo Riess ${ }^{40}$ e o IBAS (Índia, Brasil, África do Sul) cujos ministros de C\&T se reuniram em setembro/2006 para fomentar a cooperação no setor ${ }^{41}$, além de países do Mundo Árabe, parceiros em potencial. Esses grupos possuem nichos e experiências bem sucedidas em alguns setores da economia, ou ainda dispóem de muitos recursos financeiros para investir (Arábia Saudita) e são os mais importantes para cooperação efetiva com o Brasil. Com a África portuguesa, a prioridade em colaboração em C\&T se dá por meio de assistência técnica em setores como agricultura, ${ }^{42}$ saúde e cultura e esta colaboração tem recebido atenção especial da parte do atual governo brasileiro.

Para parceiros tão variados, o que o Brasil tem para oferecer para participar de alianças?

\section{Parcerias: troca de experiências e complementaridade}

O Brasil é uma nação com muito a oferecer a outras, e para receber delas também, portanto, "trocar". O País não tem litígios com vizinhos. Atua até de mediador em conflitos localizados (Equador com Peru Haiti, e Colômbia com Venezuela). Avançou em temas como defesa dos direitos humanos e meio ambiente. Contribui com a Organização das Naçôes Unidas para o retorno da paz no Timor Leste e Haiti. Progrediu reconhecidamente em democracia e respeito às leis internacionais. Estabilizou e cresceu sua economia chegando recentemente ao $11^{\circ}$ lugar em PIB no ranking mundial, na frente da Rússia e da Índia ${ }^{43}$. Moderniza suas instituições e diversifica seu parque industrial, além de participar do comércio global. Assim, passou a ser um país mais confiável, com liderança na América do Sul.

O Brasil está organizado institucionalmente em termos de C\&T há mais de cinco décadas, dispondo de interlocutores em vários níveis, desde o planejamento até instâncias decisórias. País continental, possui uma classe média de umas 75

38 Queiroz, S.R.R de. "Globalização da P\&D: oportunidades para o Brasil”, Parcerias Estratégicas, n 20, parte 5, junho de 2005, CGEE/MCT, p. 1.515-1.533

39 Trabalhos apresentados no Seminário Alianças Estratégicas para o Brasil: China e Índia, organizado pelo Gabinete de Segurança Institucional da Presidência da República, Brasília 22.7.2005.

40 Reiss, C. p. 49, “A new setting for international cooperation?” Space Policy, 2005, p. 49-53.

41 Índia, Brasil e África do Sul avançam em programa de cooperação trilateral, Agência CT/MCT 4.9.2006.

42 http://www.embrapa.br/linhas_de_acao/desenvolvimento/coop_internacional. Disponibilidade 16.11.2006.

43 Folha on line, htpp:www1.folha.uol.com.br/folha/dinheiro. Disponibilidade: 30.3.2006. 
milhões de pessoas $(-1 / 3$ da população total), representando um mercado das dimensōes do mercado de um país consumidor da Europa. Enquanto isso, a China constrói a sua classe média, os "capitalistas vermelhos", dada à sua forte vinculação com o Partido Comunista.

Dificilmente o Brasil já não assinou acordo de colaboração científica, técnica ou tecnológica com alguma nação. Somente o CNPq tem acordos chamados de "cooperação" mas que são colaboraçōes, segundo as definições adotadas no presente texto, com mais de 29 delas, envolvendo 53 instituiçôes e organizações internacionais, muitos sendo apenas intercâmbio científico ${ }^{44}$. Mesmo assim, nem todas as colaborações prosperaram, principalmente as multilateriais, ou avançam muito lentamente. ${ }^{45}$ Algumas ficam adiadas, como a Cooperação Biregional ALCUE (com a União Européia) que exibe muito mais características de colaboração do que de cooperação, apresentando dificuldades para ser implementada, como aponta Schmied ${ }^{46}$.

Países com maior experiência em firmar parcerias costumam oferecer janelas de oportunidade, via acordos bilaterais, em grandes projetos definidos e controlados por eles ${ }^{47}$ e que são colaborações e não cooperações. Outra forma, é colaborar sob a modalidade de assistência técnica e científica, mesmo em setores como espaço e nuclear; ou quanto ao uso compartilhado de grandes equipamentos, pagando uma quota, mais uma forma de colaboração apenas.

Atualmente, as parcerias com empresas brasileiras são mais eqüitativas, embora poucas ainda possam ser classificadas como tal. Os exemplos citados são sempre os mesmos, Petrobrás e Embraer, por estarem em patamar diferenciado de negociação internacional, com forte vinculação com o mercado externo, altamente competitivo e cíclico, e por isso, diversificação e flexibilização são aspectos cruciais nas suas estratégias. A propósito, alianças internacionais, portanto cooperação internacional efetiva, foram decisivas para a Petrobrás dominar a tecnologia de águas profundas. Para extrair hidrocarbonetos em grande profundidade, a empresa investiu em tecnologias associadas, como Tecnologia da Informação e novos materiais. Parceria estratégica e cooperação foram efetivamente empregadas para decrescer custos, partilhar riscos, aprender e dar um salto tecnológico. Cada uma das 3 etapas do projeto com 3 tecnologias diferentes representou posiçóes competitivas distintas em cooperação com companhias estrangeiras de petróleo e engenharia e que são: Subsea Multiphase Flow Pumping System (SBMS);

44 Relatórios CNPq, 2003, 2004 (Estatísticas Comentadas).

45 Por exemplo, o Brasil tem Acordo Quadro com a Eslovênia desde 1998 sem ter ainda sido ratificado pelo Congresso Nacional.

46 Schmied, J. no artigo "Ciência, desafios do acordo de cooperação científica EU-Brasil" discute as dificuldades burocráticas, além de problemas com repasses dos recursos financeiros pelo Brasil. Folha on line, p. 1-3, 10.10.2003 (http;//tools.folha.com.br)

47 A título de exemplo o Programa Piloto de para a Proteção das Florestas Tropicais do Brasil (PPG-7) proposto pela Alemanha ao G-7 em 1990. Vide Capacitação para Pesquisa e Desenvolvimento na Amazônia (primeiro Relatório), p. 17-22, de Paulo César G. Egler, Superintendência de Desenvolvimento da Amazônia, Brasília, 19.6.2000, mimeo, $42 \mathrm{p}$. 
Subsea Separation System (SSS) e Electrical Submersible Pumps in Subsea Wells (EPRS). A Petrobrás tomou posição mais de frente quanto à tecnologia mais desenvolvida (ESPS) para a qual a empresa liderou o consórcio. Assumiu posição mais diversificada na tecnologia mais intermediária (SSS) e mais conservadora quanto à tecnologia menos desenvolvida $(\mathrm{SBMS})^{48}$.

\section{Conhecimento científico e tácito favorecem a cooperação}

No universo científico é bem mais fácil e comum o estabelecimento de confiança entre os parceiros, pois a concorrência ocorre em originalidade de publicação e no reconhecimento social, sob forma de citações nominais, prêmios, e resultados em benefício da sociedade. Quando a pesquisa é realizada em laboratórios industriais ou em institutos tecnológicos de $\mathrm{P} \& \mathrm{D}$, as parcerias obedecem lógica diferente. Entretanto, cooperações com competidores e rivais existem, e são as mais interessantes para examinar pois expõem o conceito de complementaridade e flexibilização. A maioria das cooperaçōes internacionais apresentam este perfil.

O fluxo de conhecimento internacional é intenso quando se trata de pesquisa básica. $\mathrm{O}$ interessante dessas iniciativas é que elas criam as oportunidades (fase inicial) e raízes mais profundas que podem gerar cooperaçōes posteriormente. $\mathrm{Da}$ mesma forma, o conhecimento tácito é fundamental quando equipes internacionais cooperam, pois existem cláusulas restritivas de transferência de tecnologia em algumas áreas. A aproximação física dos parceiros facilita a transferência de conhecimento por interação, fator de valorização nas cooperações internacionais.

Aos países em desenvolvimento interessa participar de projetos de pesquisa conjunto com países em desenvolvimento para aprender com eles. Mas a recíproca é verdadeira, pois a cooperação só ocorre quando todos ganham, o que favorece o trabalho em bases mais eqüitativas, quando as negociações são bem conduzidas. Neste tipo de relação, o foco dos países desenvolvidos, em particular no Brasil, é no conhecimento tácito e na coleta de material sujeita à legislação local, como a lei brasileira contra a biopirataria, e de laboratórios naturais, como ecossistemas e o Atlântico Sul.

\section{Oportunidades e riscos para parcerias internacionais e a política externa}

O relacionamento dos países avançados com o Brasil quando apenas técnico, científico e cultural foi sempre bom. Reduzido algumas vezes, mas nunca interrompido, mesmo sob governos militares e regime ditatorial. Os problemas surgiram no plano tecnológico para o Brasil quando pretendeu ter autonomia em setores que podiam comprometer países militarmente aliados, EUA e Europa

48 United Nations, 2002, op. cit. Ref. 19. 
Ocidental, buscando colaboração com os Soviéticos nas áreas nuclear ${ }^{49}$ e de veículos espaciais ${ }^{50}$.

A falta de adesão do Brasil ao sistema internacional de proteção à propriedade industrial até 1997, quando foi assinada a lei de patentes, provocou turbulências na relação EUA-Brasil, com prejuízo sobre vários outros setores da economia. $\mathrm{O}$ Brasil, de fato, sofreu embargos tecnológicos e "resfriamento diplomático" 51 dos EUA até assinar essa lei e adotar mecanismos de disciplina e controle nuclear no mesmo ano.

Levantando a bandeira de "isenção quanto à ideologia política", desde o pós-guerra, a ciência brasileira avançou, usando intercâmbios, projetos comuns de interesse da sociedade; trocou idéias em congressos; muita parceria e ganhou legitimidade perante a comunidade internacional. A partir de 2001 ocupa 17º lugar em publicações científicas internacionais, segundo o "Institute of Scientific Information". Cientistas brasileiros participam de projetos internacionais multilaterias de impacto. A lista é qualitativamente importante e uma medida da atividade de colaboração internacional mantida pelo Brasil, membro de mais de 30 organismos científicos internacionais ${ }^{52}$.

\section{Representação brasileira em fóruns internacionais}

Acordos-quadro e convenções-quadro são discutidos e memorandos de entendimento, protocolos e tratados internacionais são assinados entre naçôes para formalizar as suas participaçôes. Funcionam como orientadores de princípios e regras gerais, mas não estipulam prazos nem obrigações específicas. Têm força de lei nos países que os ratificam, mas não asseguram as condiçôes de fazer valer suas determinaçôes ${ }^{53}$.

Os oceanos, o espaço cósmico e a Antártica são as últimas fronteiras científicas reconhecidas internacionalmente ${ }^{54}$. O seu impacto sobre o clima, reservas naturais e meio ambiente é rico em conseqüências em várias esferas, começando pela política.

Usando estatísticas desfavoráveis ao Brasil, a comunidade internacional o acusou de incapacidade e falta de vontade em deter os desmatamentos na Amazônia, até que imagens do satélite CBERS apontaram exageros. Em 2004,

49 Salles, D. Um inquérito que abalou o Brasil, Ed. Fulgor Ltda, São Paulo, 1958.

50 Santos, R. "O Programa nacional de atividades espaciais frente aos embargos tecnológicos", Parcerias Estratégicas no 7, CGEE/MCT, 1999, p. 115-128.

51 Representantes da Embaixada brasileira tiveram dificuldade para serem recebidos por autoridades políticas em Washington. Vide http://www.brasilemb.org

52 MCT, Plano Plurianual/2005.

53 Albagi, S. analisa este aspecto para a Convenção sobre Diversidade Biológica no artigo "Amazônia: fronteira geopolítica da biodiversidade" em Parcerias Estratégicas, Tiragem Especial, Centro de Gestão e Estudos Estratégicos/ MCT, Brasília, 2001, p. 5-19.

54 Programa Antártico Brasileiro, fev./2004 publicado pelo Governo Federal. 
o desmatamento voltou a ser preocupante, segundo informações do Instituto Nacional de Pesquisas Espaciais baseadas em dados de satélites fornecidos a cada 3 dias. Este fato tem implicações internacionais sérias, pois o Brasil passou a ocupar o $5^{\circ}$ lugar dentre os maiores emissores de gases causadores do buraco na camada de ozônio, posição que o torna frágil politicamente nas negociações internacionais, mas os dados de satélite são obtidos pelo Brasil e podem ser comparados com os internacionais, ambos com base científica.

O poder público e a sociedade têm o dever de manter as fronteiras da ciência preservadas para as futuras geraçōes como bens públicos. É assim que este assunto é entendido e tratado em países desenvolvidos. Por isso é que, de tempos em tempos, ressurge o discurso planetário de que a Amazônia é patrimônio da humanidade, e por isso, transcende as fronteiras geográficas e interesses nacionais, e todos têm que "tomar conta dela", internacionalizando-a"

$\mathrm{O}$ sucesso da cooperação internacional em C\&T tem como importante pressuposto, o da cooperação e articulação inicialmente em nível nacional. Se esta última não funcionar, dificilmente a primeira o fará. Um exemplo mais complexo desta relação é a organização de blocos regionais, pois vai além do relacionamento bilateral entre os participantes. Seu funcionamento coloca à prova as condições tratadas no presente trabalho para que a cooperação se estabeleça e seja efetiva.

\section{Preparação de blocos regionais: políticas públicas em ação}

Um bloco regional para funcionar precisa estar maduro em todos os aspectos, este é o principal legado que a União Européia nos deixou, através da lenta e gradativa "construção da Europa" com 23 Estados-membros, e sua participação como produtora de ciência, tecnologia e inovação.

A implantação da língua espanhola nos currículos universitários e sua exigência para alguns concursos públicos no Brasil segue a lógica da União Européia, e é resultado de fases preparatórias para uma posterior integração dos países da América Latina, bem como, da preparação do País para o cumprimento de pré-condiçốes com vistas à "construção" do Mercosul. Normas técnicas, qualificação, padronização e certificação dentro do bloco dependem da utilização de técnicas e métodos científicos e tecnológicos confiáveis, e de um sistema unificado, senão não existirá integração regional. Isto, sem dúvida, é política de C\&T para este bloco regional.

Alguns projetos/programas precisam de comprometimento político. Apropósito, este foi um fator essencial para o programa CBERS, cooperação Sul-Sul sem precedentes e exemplo de aplicação das definições e discussões do

55 Autoridades brasileiras tem refutado tais declarações, como no artigo A Amazônia não está à venda, publicado na Seção Opiniāo da Folha de São Paulo em 17.10.2006, e de autoria dos ministros Sérgio Rezende, Marina Silva e Celso Amorim, respectivamente, das pastas da C\&T, Meio Ambiente e Relaçóes Exteriores. 
presente texto, principalmente as que tratam da diferença entre colaboração e cooperação ${ }^{56}$.

Ocorrem também por iniciativa de um dos parceiros com países sem experiência nesta atividade, mas que os governantes desejam realizar para promoverem as suas políticas externas e galgarem posiçõos internacionais. Este fenômeno é provocado pelas transformações introduzidas com a nova ordem internacional do pós-guerra. As nações globalizadas redirecionaram as suas políticas externas, o que envolve muita negociação e barganhas. Na prática, tratase de um processo de trabalho conjunto no qual todos aprendem por interação. Este processo é fundamental quando a cooperação envolve múltiplos parceiros, e se constitui em ferramenta poderosa no gerenciamento de projetos/programas coletivos. ${ }^{57}$ Manter os compromissos firmados em todos os seus aspectos conta positivamente no futuro relacionamento dos parceiros.

Apoio político e respeitabilidade em fóruns internacionais são importantes para países como o Brasil que aspiram a uma posição no Conselho de Segurança da ONU e vão além, defendendo uma ampla reformulação da própria organização, tema estratégico para o Governo Federal ${ }^{58}$.

\section{Considerações Finais: oportunidades, riscos e desafios}

Entender porque, como, com quem e quando cooperar demandam conhecimento dos benefícios e riscos de fazê-lo. A absorção de conhecimentos de C\&T gerados na cooperação pelas instituições passa por esta etapa. Esta é uma condição sine qua non quando se trata de projetos estratégicos internacionais. Exceto em casos excepcionais, sujeitos a cuidados especiais e legais, a parceria pode ser usada em uma grande gama de aplicação, sem salvaguardas, e como colaboração apenas. A cooperação é o meio pelo qual o trabalho conjunto de P\&D se realiza como aliança estratégica, mas existem outras formas de trabalho conjunto, apresentados neste artigo. Distinguir qual delas é a mais adequada para cada caso demanda estratégia concertada de governo com o setor produtivo para ser bem sucedida.

Para o governo traçar políticas públicas estáveis e duradouras favorecendo a cooperação internacional, sobretudo facilitando os resultados em benefício do Brasil, políticas e ações complementares devem, necessariamente, fazer parte de estratégia do Estado brasileiro, em vários níveis, passo a passo, integrada, envolvendo muita ciência e tecnologia, mas também política interna e externa. Interna, no âmbito das próprias instituições, que deveriam trabalhar mais as

56 Silva, D. H. da. The China-Brazil Earth Resources Satellites (CBERS): policies and program, submetido ao jornal Space Policy em outubro de 2006.

57 Ohmae K., op. cit. Ref. 21.

58 Projeto Brasil 3 Tempos 50 Temas Estratégicos, Núcleo de Assuntos Estratégicos, Presidência da República, 2004, mimeo 36 páginas. 
interfaces e privilegiar as funções e os grandes temas, e não a divisão artificial a que são obrigadas a se submeter por questóes burocrático-administrativas endógenas, que estão algumas vezes, na origem dos grandes gargalos. Superposições e duplicidade de esforços são apenas o corolário da falta de reconhecimento de tais problemas, não tão raras na administração pública, pelo contrário.

Externa, na montagem de uma estratégia que integre os esforços internacionais feitos pelo Brasil em C\&T\&I (e com muita precaução no I de Inovação) e que passa, necessariamente pela compreensão do papel da comunidade de C\&T como geradora e produtora de conhecimento.

Em segundo lugar, é a necessária organização nacional prévia. Esta distinção é fundamental para os planejadores e tomadores de decisão envolvidos nas relações Norte-Sul, Sul-Sul, inter e intra blocos regionais.

Instrumento poderoso para impulsionar atividades importantes para o Brasil, a cooperação internacional exige respeito aos seus condicionantes. Confiança, compromisso, respeito a prazos e repasses financeiros para o projeto comum são cruciais na cooperação Como os recursos tangíveis e intangíveis são escassos, existe uma tendência mundial de que só permaneçam com apoio financeiro, os projetos/programas que gerem resultados de mais curto prazo, ou que o impacto contribua efetivamente para o desenvolvimento da economia, ou ainda, muito emblemáticos. Esta é também a posição do atual governo brasileiro ${ }^{59}$.

As oportunidades para o Brasil são muitas. Cooperações podem ser firmadas por representantes de agências com organismos internacionais; entre universidades e institutos de pesquisa nacionais e internacionais, entre instituições de pesquisa e empresas visando a colaboração bilateral; além da formação de redes, "clusters", consórcios, ${ }^{60} \mathrm{sem}$ necessariamente autorização oficial, exceto nos casos previstos na Constituição Federal. Estes mecanismos são importantes na medida em que as maiores iniciativas de colaboração científica e tecnológica envolvendo países em desenvolvimento são do tipo Norte-Sul que podem avançar para cooperaçóes, se os pré-requisitos discutidos neste artigo forem satisfeitos.

Quanto aos riscos de participar de parcerias internacionais, existe a possibilidade de efeitos anticompetitivos, nos casos em que as alianças colocam os competidores lado a lado em um mercado. Os países mais desenvolvidos tendem a se impor sobre os menos desenvolvidos, através de suas firmas, podendo mudar de estratégia sem os outros, o que já não é tão fácil, quando cooperação está envolvida, devido à indispensável confiança e independência entre os parceiros.

Manter os compromissos internacionais em termos de prazos, padrão técnico, e fluxo de liberação de recursos financeiros representa um gargalo para países em desenvolvimento, como o Brasil. Existe um leque de opções políticas

59 O Sistema de Gerenciamento do Ministério do Planejamento (SIGPLAN) faz o acompanhamento e avaliação dos projetos na esfera federal, e assim detecta os que estão com problemas.

60 Narula, R.; Hagedoorn, J. Innovation through strategic alliances: moving towards international partnerships and contractual agreements, Technovation 19, May 1999, p. 283-294. 
para o País aumentar o número de parcerias, e por meio delas, a competitividade das firmas. Entretanto, dependem de o governo sinalizar com os seus objetivos, pois falta ao Brasil um projeto nacional de desenvolvimento. Em tempos de democracia, a sinalização do governo ainda é importante. O setor privado não é audacioso. Além disso, é fundamental distinguir-se as lógicas dos setores público e privado para não criar expectativas inúteis. A parceria é interessante para ambos, mas de maneira complementar, e não substitutiva e, por isso, a cooperação é um instrumento importante. Existem atividades que são de Estado, em qualquer lugar do mundo, pois dizem respeito a bens públicos, segurança e pesquisa genérica de alto risco e longo prazo.

Em termos de desafios, um papel nobre do governo brasileiro seria o de favorecer um ambiente de negócios para cooperação, com estabilidade macroeconômica, arcabouço legal ágil e credibilidade; infra-estrutura revitalizada e diminuição dos juros para incentivar parcerias entre firmas.

Alguns dos pontos enfatizados no presente trabalho foram destacados por Krieger e Góes como desafios para que a cooperação Norte-Sul traga benefícios para o Brasil. São eles:

"Incrementar a cooperação institucional com a participação do MCT e suas agências, do Ministério das Relaçóes Exteriores e a Academia Brasileirade Ciências;

Evitar a assimetria entre as equipes e grupos que cooperam de forma que se evite que os investimentos realizados não tenham continuidade. É fundamental que as equipes e os programas tenham estabilidade nas equipes e no financiamento;

Seguindo a tendência mundial, a cooperação multilateral deve ser privilegiada, não em detrimento da cooperação bilateral mas como um mecanismo mais ágil para a formação de redes de colaboração entre pesquisadores." ${ }^{61}$

Recebido em 10 de outubro de 2006 Aprovado em 5 de janeiro de 2007

\section{Resumo}

O artigo analisa diferenças entre cooperação e colaboração científica e tecnológica. A cooperação internacional representa oportunidades para parceiros sobretudo as alianças estratégicas. Na colaboração Norte-Sul geralmente os países desenvolvidos definem o projeto/programa e detém a propriedade dos resultados. Reconhecer estas diferenças representa desafios e oportunidades mas também riscos para o Brasil.

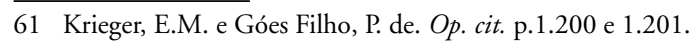




\section{Abstract}

This article analyses differences between scientific and technological co-operation and collaboration. International cooperation represents opportunities for partners, mainly strategic alliances. In North-South collaborations usually developed countries define the project/program and become the sole owner of the results. Opportunities and risks for countries such as Brazil are to recognize these differences.

Palavras-chave: Cooperação Internacional em Ciência e Tecnologia, alianças estratégicas. Key words: International Cooperation in Science and Technology, strategic alliances. 